\title{
KLASIFIKASI SEKOLAH MENENGAH PERTAMA/SEDERAJAT WILAYAH BIREUEN MENGGUNAKAN ALGORITMA K-NEAREST NEIGHBORS BERBASIS WEB
}

\author{
Rozzi Kesuma Dinata ${ }^{1}$, Fajriana ${ }^{2}$ Zulfa $^{3}$, Novia Hasdyna ${ }^{4}$ \\ 1,2,3 Program Studi Teknik Informatika Universitas Malikussaleh \\ Jl. Kampus Unimal Bukit Indah, Blang Pulo, Lhokseumawe, Aceh, Indonesia \\ ${ }^{4}$ Program Studi Teknik Informatika Universitas Islam Kebangsaan Indonesia \\ Jl. Medan - Banda Aceh Sp. Alue Awe, Lhokseumawe, Aceh, Indonesia \\ ${ }^{1}$ rozzi@unimal.ac.id, ${ }^{2}$ fajriana@unimal.ac.id, ${ }^{3}$ umiulfa5@gmail.com, ${ }^{4}$ noviahasdyna@gmail.com
}

\begin{abstract}
Abstrak- Pada penelitian ini diimplementasikan algoritma K-Nearest Neighbor dalam pengklasifikasian Sekolah Menengah Pertama/Sederajat berdasarkan peminatan calon siswa. Tujuan penelitian ini adalah untuk memudahkan pengguna dalam menemukan sekolah SMP/sederajat berdasarkan 8 kriteria sekolah yaitu akreditasi, fasilitas ruangan, fasilitas olah raga, laboratorium, ekstrakulikuler, biaya, tingkatan kelas dan waktu belajar. Adapun data yang digunakan dalam penelitian ini didapatkan dari Dinas Pendidikan Pemuda dan Olahraga Kabupaten Bireuen. Hasil penelitian dengan menggunakan K-NN dan pendekatan Euclidean Distance dengan $\mathrm{k}=3$, diperoleh nilai precision sebesar $63,67 \%$, recall $68,95 \%$ dan accuracy sebesar $79,33 \%$.
\end{abstract}

Kata Kunci- Klasifikasi, K-Nearest Neighbor, Euclidean Distance, Akurasi

Abstract- In this research, the K-Nearest Neighbor algorithm was implemented in the classification of junior high schools/equivalent based on the interest of prospective students. The purpose of this study is to facilitate users in finding junior high schools/equivalent based on 8 school criteria, namely accreditation, room facilities, sports facilities, laboratories, extracurricular activities, fees, grade levels and study time. The data used in this study were obtained from the Bireuen District Youth and Sports Education Office. The results of the study using K-NN and Euclidean Distance approach with $k=3$, obtained precision values of $63.67 \%$, recall $68.95 \%$ and accuracy of $79.33 \%$.

Keywords - Classification, K-Nearest Neighbor, Euclidean Distance, Accuracy

\section{PENDAHULUAN}

Wilayah Bireuen terdiri dari 17 Kecamatan. Setiap kecamatan terdapat 5 sampai 8 SMP/MTS yang keseluruhannya mencapai 111 Sekolah, 86 SMP dan 25 MTS. Setiap sekolah memiliki kriteria atau fasilitas yang berbeda-beda, baik fasilitas ruangan, olah raga, ekstrakulikuler, akreditasi, biaya dan lain sebagainya.

Pada penelitian ini penulis mengimplementasikan algoritma k-nearest neighbor dalam membangun sebuah sistem yang akan memudahkan masyarakat dalam mengakses dan mendapatkan informasi terkait sekolah-sekolah yang memiliki keunggulan baik dibidang fasilitas pendidikan, ekstrakulikuler dan yang lainnya.

K-Nearest Neighbor (KNN) adalah salah satu algoritma data mining yang bisa digunakan dalam klasifikasi data [1].

\section{A. K-Nearest Neighbor}

\section{TINJAUAN PUSTAKA}

K-Nearest Neighbor merupakan salah satu metode yang digunakan dalam pengklasifikasian [2]. Adapun langkah-langkah penggunaan metode K-NN ini dijelaskan sebagai berikut[3]:

1. Tentukan parameter $\mathrm{K}$

2. Hitung jarak antara data yang akan dievaluasi dengan semua pelatihan

3. Urutkan jarak yang terbentuk (urut naik)

4. Tentukan jarak terdekat sampai urutan $\mathrm{K}$

5. Pasangkan kelas yang bersesuaian

6. Cari jumlah kelas dari tetangga yang terdekat dan tetapkan kelas tersebut sebagai kelas data yang akan dievaluasi [4].

Ada beberapa Metode Pendekatan K-NN. Dalam penelitian ini Metode Pendekatan yang digunakan adalah Metode Pendekatan Euclidean Distance. Berikut adalah rumus untuk mencari nilai akar dari kuadrat dua vector[5].

$$
d_{i}=\sqrt{\sum_{i=1}^{p}\left(x_{2 i}-x_{1 i}\right)^{2}}
$$

Keterangan: $\mathrm{x} 1$ = Sampel data 
x2 = Data uji atau data testing

$\mathrm{i}=$ Variabel data

$\mathrm{d}=$ Jarak

$\mathrm{p}=$ Jumlah data training

Page| 34 B. Confusion Matrix

Confussion matrix melakukan pengujian untuk memperkirakan obyek yang benar dan salah. [6].

TABEL I

CONFUSION MATRIX

\begin{tabular}{|c|c|c|}
\hline \multirow{2}{*}{ Nilai prediksi } & \multicolumn{2}{|c|}{ Nilai Aktual } \\
\cline { 2 - 3 } & $\mathrm{TP}$ & $\mathrm{TN}$ \\
\cline { 2 - 3 } & $\mathrm{FP}$ & $\mathrm{TN}$ \\
\hline
\end{tabular}

Keterangan :

$\mathrm{TP}=$ True postif

$\mathrm{TN}=$ True negatif

$\mathrm{FP}=$ False positif.

$\mathrm{FN}=$ False negatif

Rumus untuk perhitungan confusion matrix jika di tuliskan seperti dibawah ini:

a. Precision digunakan untuk mengukur tingkat ketepatan antara informasi yang diminta oleh pengguna dengan jawaban yang diberikan oleh sistem.

$$
\text { Precision }=\frac{\mathrm{TP}}{\mathrm{TP}+\mathrm{FP}}
$$

b. Recall digunakan untuk mengukur tingkat keberhasilan sistem dalam menemukan kembali sebuah informasi, pada persamaan.

$$
\text { Recall }=\frac{\mathrm{TP}}{\mathrm{TP}+\mathrm{FN}}
$$

c. Accuracy digunakan untuk mengukur kinerja sebuah metode [8].

$$
\text { Accuracy }=\frac{T P+T N}{T P+T N+F P+F N}
$$

\section{METODOLOGI PENELITIAN}

Adapun alur penelitian ini dapat dilihat pada diagram alir penelitian berikut.

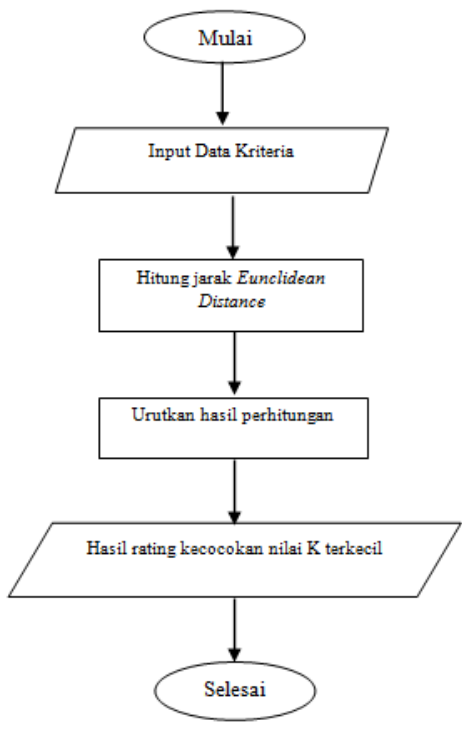

Gbr. 1 Skema Sistem Klasifikasi Sekolah SMP dan MTS Wilayah Bireuen

\section{HASIL DAN PEMBAHASAN}

A. Manajemen Basis Data

1.Tabel_Admin

TABEL II

ADMIN

\begin{tabular}{|c|c|c|c|c|}
\hline No & Nama & Type & Width & Keterangan \\
\hline 1 & admin_id & Int & 11 & Primary key \\
\hline 2 & admin_username & Varchar & 50 & $\begin{array}{c}\text { Username } \\
\text { admin }\end{array}$ \\
\hline 3 & admin_password & Varchar & 50 & $\begin{array}{c}\text { Password } \\
\text { admin }\end{array}$ \\
\hline
\end{tabular}

2. Tabel_DataSekolah

TABEL III

DATA SEKOLAH

\begin{tabular}{|c|c|c|c|c|}
\hline No & Nama & Type & Width & Keterangan \\
\hline 1 & id & Int & 5 & Primary key \\
\hline 2 & $\begin{array}{c}\text { nama_se } \\
\text { kolah }\end{array}$ & varchar & 50 & Nama sekolah \\
\hline 3 & latitude & float & - & $\begin{array}{c}\text { Titik koordinat } \\
\text { sekolah }\end{array}$ \\
\hline 4 & longitude & float & - & $\begin{array}{c}\text { Titik koordinat } \\
\text { sekolah }\end{array}$ \\
\hline
\end{tabular}

3. Tabel_DataTraining

TABEL IV

DATA TRAINING

\begin{tabular}{|c|c|c|c|c|}
\hline No & Nama & Type & Width & Keterangan \\
\hline 1 & id & Int & 5 & Primary key \\
\hline 2 & nama_sekolah & varchar & 100 & Nama sekolah \\
\hline 3 & X1 & Int & 5 & Akreditasi \\
\hline 4 & X2 & Int & 5 & Fasilitas ruangan \\
\hline 5 & X3 & Int & 5 & $\begin{array}{c}\text { Fasilitas } \\
\text { olahraga }\end{array}$ \\
\hline 6 & X4 & Int & 5 & Laboratorium \\
\hline 7 & X5 & Int & 5 & Biaya perbulan \\
\hline 8 & X6 & Int & 5 & Ekstrakulikuler \\
\hline
\end{tabular}




\begin{tabular}{|c|c|c|c|c|}
\hline 9 & $\mathrm{X} 7$ & Int & 5 & Tingkatan kelas \\
\hline 10 & $\mathrm{X} 8$ & Int & 5 & Waktu Belajar \\
\hline 11 & klasifikasi & varchar & 50 & $\begin{array}{c}\text { Rekomendasi } \\
\text { sekolah }\end{array}$ \\
\hline 12 & value & Int & 5 & Value \\
\hline
\end{tabular}

\begin{tabular}{|c|c|c|c|c|c|}
\hline Jumlah & 49 & 11 & 11 & 109 & 180 \\
\hline
\end{tabular}

TABEL X

PREDICTED CLASS $\mathrm{K}=2$

Page| 35 4. Tabel_Data Kriteria

TABEL V

DATA KRITERIA

\begin{tabular}{|c|c|c|c|c|}
\hline No & Nama & Type & Width & Keterangan \\
\hline 1 & id & Int & 11 & Primary key \\
\hline 2 & kode & Varchar & 10 & Kode criteria \\
\hline 3 & nama & Varchar & 50 & Nama criteria \\
\hline
\end{tabular}

5. Tabel_Data Sub Kriteria

TABEL VI

DATA SUB KRITERIA

\begin{tabular}{|c|c|c|c|c|}
\hline No & Nama & Type & Width & Keterangan \\
\hline 1 & sub_id & Int & 5 & Primary key \\
\hline 2 & kode_kriteria & Varchar & 10 & Kode criteria \\
\hline 3 & Value & Varchar & 100 & Value \\
\hline 4 & bobot & Int & 5 & Bobot \\
\hline
\end{tabular}

\begin{tabular}{|c|c|c|c|c|}
\hline Class Prediksi & $\begin{array}{c}\text { Sangat } \\
\text { Rekomen } \\
\text { dasi }\end{array}$ & $\begin{array}{c}\text { Rekom } \\
\text { en-dasi }\end{array}$ & $\begin{array}{c}\text { Kurang } \\
\text { Rekomen } \\
\text { dasi }\end{array}$ & $\begin{array}{c}\text { Juml } \\
\text { ah }\end{array}$ \\
\hline $\begin{array}{c}\text { Sangat } \\
\text { Rekomendasi }\end{array}$ & 5 & 6 & 0 & 11 \\
\hline Rekomendasi & 8 & 28 & 4 & 40 \\
\hline $\begin{array}{c}\text { Kurang } \\
\text { Rekomendasi }\end{array}$ & 0 & 2 & 7 & 9 \\
\hline Jumlah & 13 & 36 & 11 & 60 \\
\hline
\end{tabular}

TABEL XI

CONFUSION MATRIX $K=2$

\begin{tabular}{|c|c|c|c|c|c|}
\hline $\begin{array}{c}\text { Confussion } \\
\text { Matrix }\end{array}$ & TP & FP & FN & TN & Jumlah \\
\hline $\begin{array}{c}\text { Sangat } \\
\text { Rekomendasi }\end{array}$ & 5 & 8 & 6 & 41 & 60 \\
\hline Rekomendasi & 28 & 8 & 12 & 12 & 60 \\
\hline $\begin{array}{c}\text { Kurang } \\
\text { Rekomendasi }\end{array}$ & 7 & 4 & 2 & 47 & 60 \\
\hline Jumlah & 40 & 20 & 20 & 100 & 180 \\
\hline
\end{tabular}

B. Hasil Perhitungan Jarak dengan Euclidean Distance

TABEL VII

HASIL PERHITUNGAN JARAK 1

\begin{tabular}{|c|c|c|c|}
\hline No & Jarak & Class & $\mathbf{k}$ \\
\hline 1 & 1 & Sangat Rekomendasi & 1 \\
\hline 27 & 1 & Sangat Rekomendasi & 2 \\
\hline 30 & 2 & Sangat Rekomendasi & 3 \\
\hline
\end{tabular}

Berdasarkan nilai jarak yang telah diperoleh dari hasil perhitungan data testing 1 terhadap 140 data training,nilai jarak terkecil didapatkan pada data ke-1, ke-27 dan data ke-30.

\section{Hasil Perhitungan Akurasi K-NN}

Perhitungan akurasi didapatkan dengan confusion matrix.

TABEL VIII

PREDICTED CLASS $\mathrm{K}=1$

\begin{tabular}{|c|c|c|c|c|}
\hline Class Prediksi & $\begin{array}{c}\text { Sangat } \\
\text { Rekomen } \\
\text { dasi }\end{array}$ & $\begin{array}{c}\text { Rekomen } \\
\text { dasi }\end{array}$ & $\begin{array}{c}\text { Kurang } \\
\text { Rekomen } \\
\text { dasi }\end{array}$ & $\begin{array}{c}\text { Juml } \\
\text { ah }\end{array}$ \\
\hline $\begin{array}{c}\text { Sangat } \\
\text { Rekomendasi }\end{array}$ & 7 & 4 & 0 & 11 \\
\hline Rekomendasi & 3 & 34 & 3 & 40 \\
\hline $\begin{array}{c}\text { Kurang } \\
\text { Rekomendasi }\end{array}$ & 0 & 1 & 8 & 9 \\
\hline Jumlah & 10 & 39 & 11 & 60 \\
\hline
\end{tabular}

TABEL IX

CONFUSION MATRIX $K=1$

\begin{tabular}{|c|c|c|c|c|c|}
\hline \multicolumn{6}{c|}{ CONFUSION MATRIX $K=1$} \\
\hline $\begin{array}{c}\text { Matrix } \\
\text { Sangat } \\
\text { Rekomendasi }\end{array}$ & 7 & 3 & 4 & 46 & 60 \\
\hline Rekomendasi & 34 & 5 & 6 & 15 & 60 \\
\hline $\begin{array}{c}\text { Kurang } \\
\text { Rekomendasi }\end{array}$ & 8 & 3 & 1 & 48 & 60 \\
\hline
\end{tabular}

TABEL XII

PREDICTED CLASS $\mathrm{K}=3$

\begin{tabular}{|c|c|c|c|c|}
\hline Class Prediksi & $\begin{array}{c}\text { Sangat } \\
\text { Rekomend } \\
\text { asi }\end{array}$ & $\begin{array}{c}\text { Rekome } \\
\text { n-dasi }\end{array}$ & $\begin{array}{c}\text { Kurang } \\
\text { Rekomend } \\
\text { asi }\end{array}$ & $\begin{array}{c}\text { Juml } \\
\text { ah }\end{array}$ \\
\hline $\begin{array}{c}\text { Sangat } \\
\text { Rekomendasi }\end{array}$ & 6 & 5 & 0 & 11 \\
\hline Rekomendasi & 8 & 23 & 9 & 40 \\
\hline $\begin{array}{c}\text { Kurang } \\
\text { Rekomendasi }\end{array}$ & 0 & 2 & 7 & 9 \\
\hline Jumlah & 14 & 30 & 16 & 60 \\
\hline
\end{tabular}

TABEL XIII

CONFUSION MATRIX $K=3$

\begin{tabular}{|c|c|c|c|c|c|}
\hline $\begin{array}{c}\text { Confussion } \\
\text { Matrix }\end{array}$ & TP & FP & FN & TN & Jumlah \\
\hline $\begin{array}{c}\text { Sangat } \\
\text { Rekomendasi }\end{array}$ & 6 & 8 & 5 & 41 & 60 \\
\hline Rekomendasi & 23 & 7 & 17 & 13 & 60 \\
\hline $\begin{array}{c}\text { Kurang } \\
\text { Rekomendasi }\end{array}$ & 7 & 9 & 2 & 42 & 60 \\
\hline Jumlah & 36 & 24 & 24 & 96 & 180 \\
\hline
\end{tabular}

Adapun hasil perhitungan akurasi dapat dilihat pada tabel 14

TABEL XIV HASIL PERHITUNGAN AKURASI

\begin{tabular}{|c|c|c|c|c|}
\hline $\mathbf{k}$ & Precision & Recall & & Akurasi \\
\hline $\mathrm{k}=1$ & 0,766355866 & 0,791750842 & & 0,877777778 \\
\hline $\mathrm{k}=2$ & 0,5995856 & 0,644107744 & & 0,777777778 \\
\hline $\mathrm{k}=3$ & 0,544246032 & 0,632744108 & & 0,733333333 \\
\hline Jumlah & 0,636729166 & 0,689534231 & & 0,796296296 \\
\hline Persentase & $63,67 \%$ & $68,95 \%$ & & $79,62 \%$ \\
\hline
\end{tabular}

Berdasarkan tabel 14, dapat dilihat grafik berikut. 


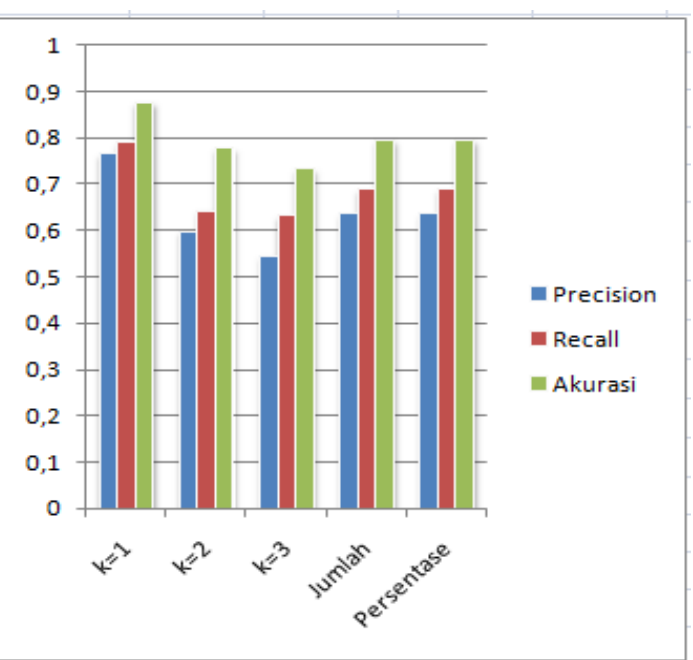

Gbr. 2 Grafik Nilai Akurasi K-NN pada Klasifikasi Sekolah SMP dan MTS Wilayah Bireuen

\section{Implementasi Sistem}

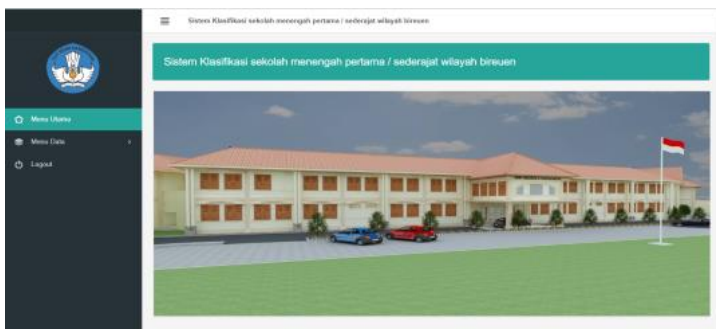

Gbr 3. Tampilan Menu Utama

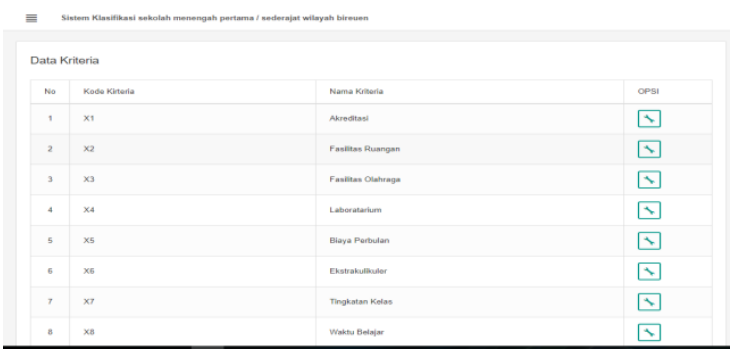

Gbr. 4 Tampilan Halaman kriteria
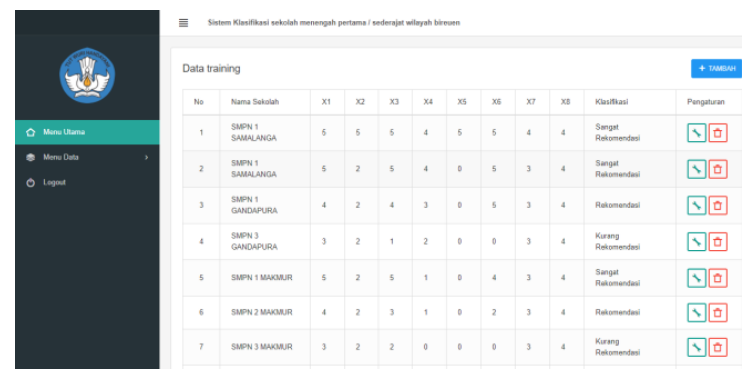

Gbr. 5 Tampilan Data Training

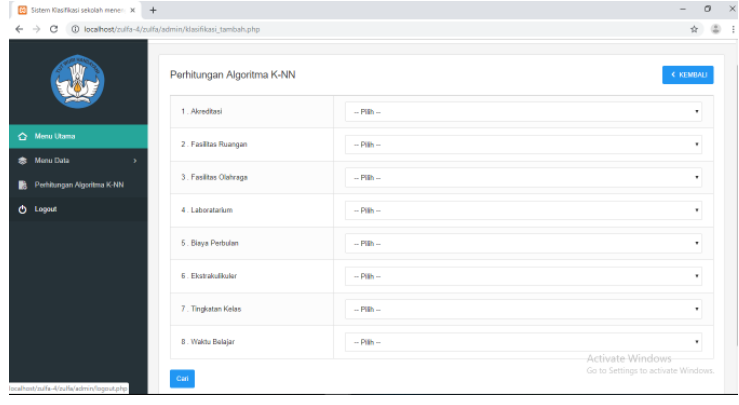

Gbr. 6 Menu Pilihan Kriteria

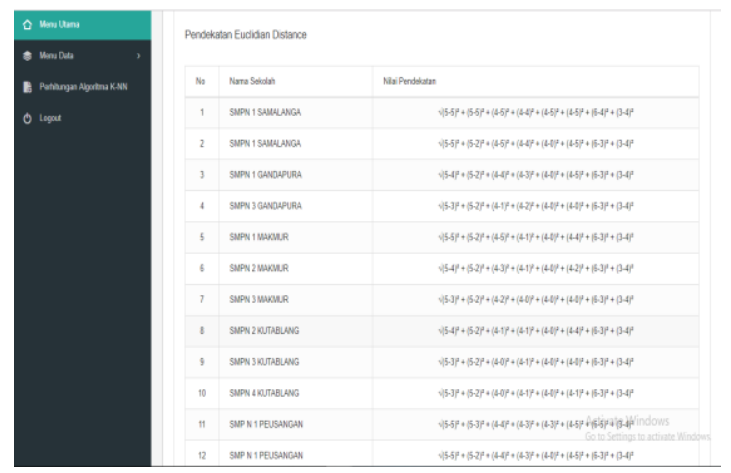

Gbr. 7 Perhitungan algoritma K-NN

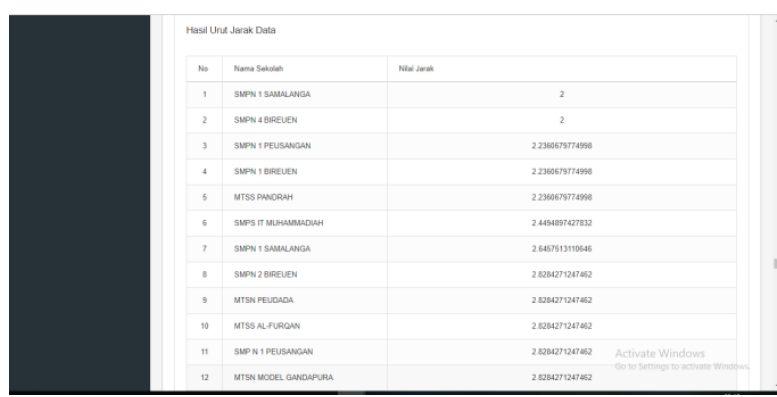

Gbr. Hasil Perhitungan Jarak
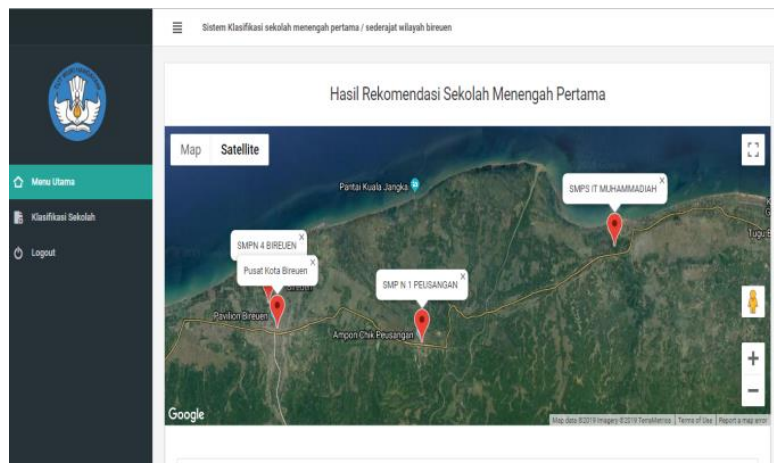

Gbr.9 Hasil Rekomendasi sekolah dengan K-NN

\section{PENUTUP}

Hasil penelitian yang telah dilakukan terhadap 140 data training dan 60 data testing didapatkan hasil akhir berupa sekolah yang paling mendekati berdasarkan kriteria yang diinginkan. Dengan $k=3$ diperoleh rata-rata nilai akurasi sebesar $79,62 \%$. 
Persentase tersebut menunjukkan bahwa algoritma $K$ Nearest Neighbor memiliki kinerja yang baik dan akurat dalam menglasifikasikan data sekolah SMP dan MTS di wilayah Bireuen.

\section{REFERENSI}

Page | 37 [1] Luthfi Anshori, Rekyan Regasari Mardi Putri, Tibyani, "Implementasi Metode K-Nearest Neighbor untuk Rekomendasi Keminatan Studi (Studi Kasus: Jurusan Teknik Informatika Universitas Brawijaya)", Jurnal Pengembangan Teknologi Informasi dan Ilmu Komputer, Vol. 2, No. 7, Juli 2018, hlm. 2745-2753

[2] Sumarlin, "Implementasi Algoritma K-Nearest Neighbor Sebagai Pendukung Keputusan Klasifikasi Penerima Beasiswa PPA dan BBM," Jurnal Sistem Informasi Bisnis, 13 April 2015.

[3] H. Risman, D. Nugroho, and Y. R. WU, "Penerapan Metode K-Nearest Neighbor Pada Aplikasi," Jural TIKomSiN, vol. 3, no. 2, pp. 19-25, 2013

[4] Yeni Kustiyahningsih and N. Syafa'ah, "Sistem Pendukung Keputusan Untuk Menentukan Jurusan Pada Siswa Sma Menggunakan Metode Knn Dan Smart," Jsii, vol. 1, no. 1, pp. 19-28, 2014

[5] M. M. K. Neighbor, "Seleksi Pegawai dan Dosen UMRI Berbasis E-Recruitment," pp. 71-80.

[6] J. T. Informatika, F. I. Komputer, and U. D. Nuswantoro, "Berdasarkan Enam Tipe Pattern Menggunakan Metode Euclidean," pp. 1-5.

[7] I. Menarianti, "Klasifikasi data mining dalam menentukan pemberian kredit bagi nasabah koperasi," J. Ilm. Teknosains, vol. 1, no. 1, pp. 1-10, 2015.

[8] J. Riany, M. P. Lukman, and M. Fajar, "Penerapan Deep Sentiment Analysis pada Angket Penilaian Terbuka Menggunakan K-Nearest Neighbor,” Sisfo, vol. 06, no. 01, pp. 147-156, 2017.

[9] Dyah Ayu Wulandari,"Implementasi Data Mining Untuk Menentukan Penjurusan Sekolah Menengah Atas Menggunakan Algoritma K-Nearest Neighbor Klasifikasi Pada SMAN 1 PACE”, Simki-Techsain vol. 01 No . 10 tahun 2017. 